\title{
Ruina, alegoría y anamnesis**. El ejercicio de la memoria sobre la des-aparición del ex ferrocarril de cintura de Santiago
}

\author{
Ruin, allegory and anamnesis. \\ The practice of memory over the dis-appearence of the ex-railway belt of Santiago
}

$<$ Resumen>

Como hecho material concreto en la realidad urbana, los territorios de la ex circunvalación ferroviaria de Santiago aparecen, en la medida que desaparecen. Esto es, que su presencia actual en la ciudad, es mayormente la de una infraestructura residual, en distintos estados de desaparición, y como tal, se of rece a la experiencia del habitante.

$<$ Abstract>

Considered as a fact in urban reality, the ex-railway belt territories of Santiago appear, as they disappear. That is to say, that its presence in the city, is mainly one of a residual infrastructure, in different conditions of disappearance; and as such, it is experienced by the inhabitants.

<PALABRAS CLAVE>

RUINA / TERRAIN VAGUE / MEMORIA / ANAMNESIS / ALEGORÍA

<KEYWORDS>

RUIN / TERRAIN VAGUE / MEMORY / ANAMNESIS / ALLEGORY

\section{Ruina}

Las infraestructuras que darían paso a la antigua circunvalación férrea de Santiago se dispusieron en los bordes de la ciudad hacia finales del siglo xIx, configurando un límite en torno al cual se aglutinó su actividad productiva y su intercambio con el exterior. Esta red marcaba así, en un inicio, la diferencia entre una ciudad con una estructura urbana más bien consolidada, hacia el interior; y los crecimientos dispersos que se daban hacia las afueras, de carácter más bien rural.

Pero pocas décadas después, dos importantes obras marcaron el comienzo de un proceso de retraimiento de este sistema frente al avance de la ciudad, que en ese momento ya sobrepasaba este antiguo límite. La primera fue el soterramiento de la línea férrea que pasaba por la Avenida Matucana, para resolver el conflicto que producía el paso del ferrocarril que prácticamente cercenaba la relación del centro hacia los sectores densamente poblados en torno de la Quinta Normal. La construcción del túnel comenzó en 1937 y terminó en 1945, y una vez finalizado, permitió una mayor continuidad a nivel de trama, así como la transformación de Matucana en un eje urbano de gran riqueza e intensidad de relaciones; $y$ todo esto, manteniendo el sistema ferroviario en funcionamiento. La segunda corresponde al levantamiento de la Estación Providencia y su patio de maniobras, que dificultaba la continuidad urbana hacia el emergente barrio que se desarrollaba al costado oriente de la

* Arquitecto Universidad de Chile, Magister en Arquitectura, Universidad Católica de Chile.

* Este artículo está basado en la Tesis de Magíster del autor, titulada: Paisaje de la Ausencia Claves para una interpretación sobre los territorios del ex anillo ferroviario de Santiago, puntualmente del capítulo: Ex Estación Yungay. Los márgenes críticos de la memoria. Profesor guía: Wren Strabucchi Chambers. 
ciudad. En el vacío dejado por la estación y su infraestructura asociada, se construyó el Parque Bustamante, entre los años 1941 y 1945. Su antiguo entorno productivo se convirtió en un sector predominantemente residencial, y el trazado oriente del ferrocarril de cintura retrocedió hacia el sur, ubicándose como terminal la nueva Estación Ñuñoa, sólo para transporte de carga, al sur de la Avenida Grecia. A estas alturas, la primera condición de borde externo del anillo ferroviario ${ }^{1}$, daba paso a la de una periferia interior. Esta situación hizo crisis, al punto de que se produjeron estas dos grandes intervenciones urbanas, con el ferrocarril como tecnología aún vigente y en pleno funcionamiento ${ }^{2}$

Sin embargo, los posteriores procesos de intervención sobre los territorios ferroviarios, producidos principalmente desde la década de los 90, se harían sobre una infraestructura subutilizada y en franca decadencia. La obsolescencia funcional del sistema determinó su abandono y letargo, dando lugar a un conjunto de vacíos situados en torno al antiguo centro de la ciudad. Aún hoy, un buen porcentaje de estos sectores permanece en esta condición; y más allá de la especulación que se pueda tejer en torno a su futuro, persisten en tanto hecho material concreto, como un territorio en ruinas.

Las ruinas, como estado caduco de una construcción o lugar, evocan de modo incierto su constitución anterior y la vida que alojaron. En su condición inacabada remiten siempre a una ausencia, que está mediando entre lo anterior y lo imaginado.

(...) si la ruina da mucho que pensar (por su configuración material), es probablemente porque expresa una Idea de la imaginación, más que una Idea de la razón ${ }^{3}$.

Se propone aquí, hacer extensiva la lectura de ruina desde el objeto al territorio, es decir, que más allá de contener ciertos elementos «en ruinas», es el territorio mismo, el ex anillo de circunvalación ferroviaria de Santiago, una ruina. Lo son tanto los viejos galpones y vagones oxidados, como los mismos lugares abandonados y poblados de maleza que contienen estos objetos; y que en

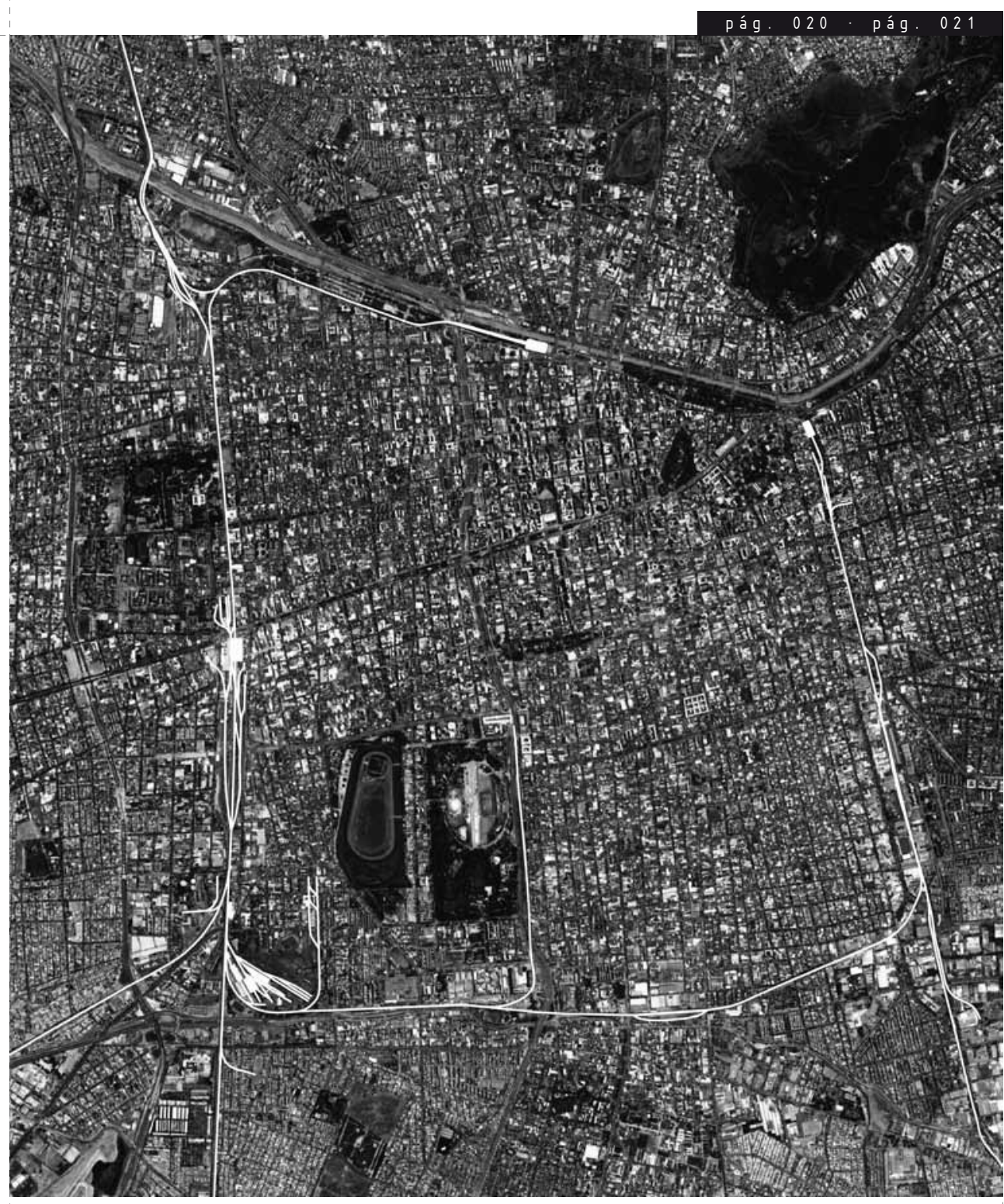

Principales trazados férreos de Santiago en base al Plano de Catastro de 1933. Catastro Municipal de Santiago. Gentileza Álvaro Salas y Wren Strabucchi. Superpuestos sobre una fotografía aérea de la ciudad, del año 2008 de Google Earth. Imagen elaborada por el autor. Se marcan las principales estaciones del sistema. La Estación Alameda en la mitad del trazado poniente; y las Estaciones Mapocho y Providencia como terminales de los trazados por el norte y el nororiente, respectivamente.

conjunto suman una serie de fragmentos que configuran la débil huella de un paisaje en desaparición. Y siguiendo adelante con esta correspondencia entre la ruina como objeto y la ruina como territorio, se pueden comprender aquellas piezas del sistema ferroviario que han desaparecido al dar paso a nuevas porciones de ciudad, como en el caso mencionado de la antigua Estación Providencia, como aquellas porciones ya desaparecidas de la ruina: aquello que falta en la reconstitución de una totalidad ya desaparecida. Pero en estas

Como tal, el anillo nunca alcanzó a constituirse, quedando discontinuo entre las estaciones Providencia y Mapocho; dejando libre el paso por el Camino de Providencia hacia el oriente, y hacia el norte la conexión directa entre la Plaza de Armas, el Mercado Central y la calle Independencia, otrora «El Camino de Chile», antigua ruta de acceso a la ciudad desde el norte. Esta apertura determinó la mayor expansión de la ciudad fuera de los límites del ferrocarril, en las primeras décadas del siglo pasado.

De hecho, para mitigar el impacto de la eliminación de la Estación Providencia en el sistema, se produjeron sendos trabajos de remodelación en el sector de Yungay (esquina norponiente del anillo); y se construyó una nueva «Estación Ñuñoa» (sur-oriente), dando paso a una reconfiguración del sistema de vías en el sector suroriente de la circunvalación.

Jean Louis Déotte. Catástrofe y olvido. Las ruinas, Europa, el museo. Santiago: Editorial Cuarto Propio, 1998; p. 50. Traducción de Justo Pastor Mellado del título original Oubliez! Les ruines, l'Europe le Musée. París: Éditions L'Harmattan, 1994. 


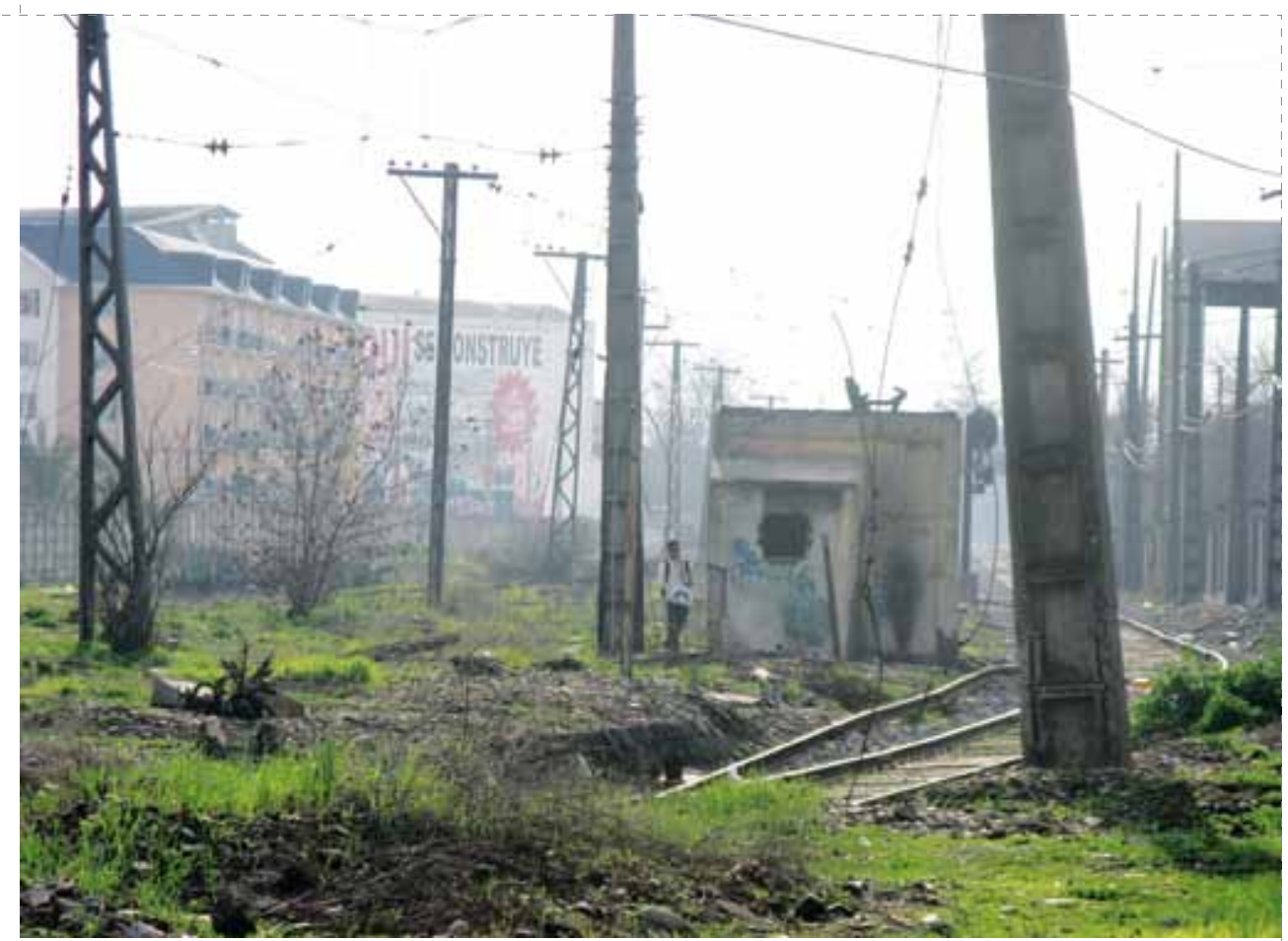

Entorno de la ex Estación Yungay de Ferrocarriles, Santiago, julio de 2008 Fotografía del autor.

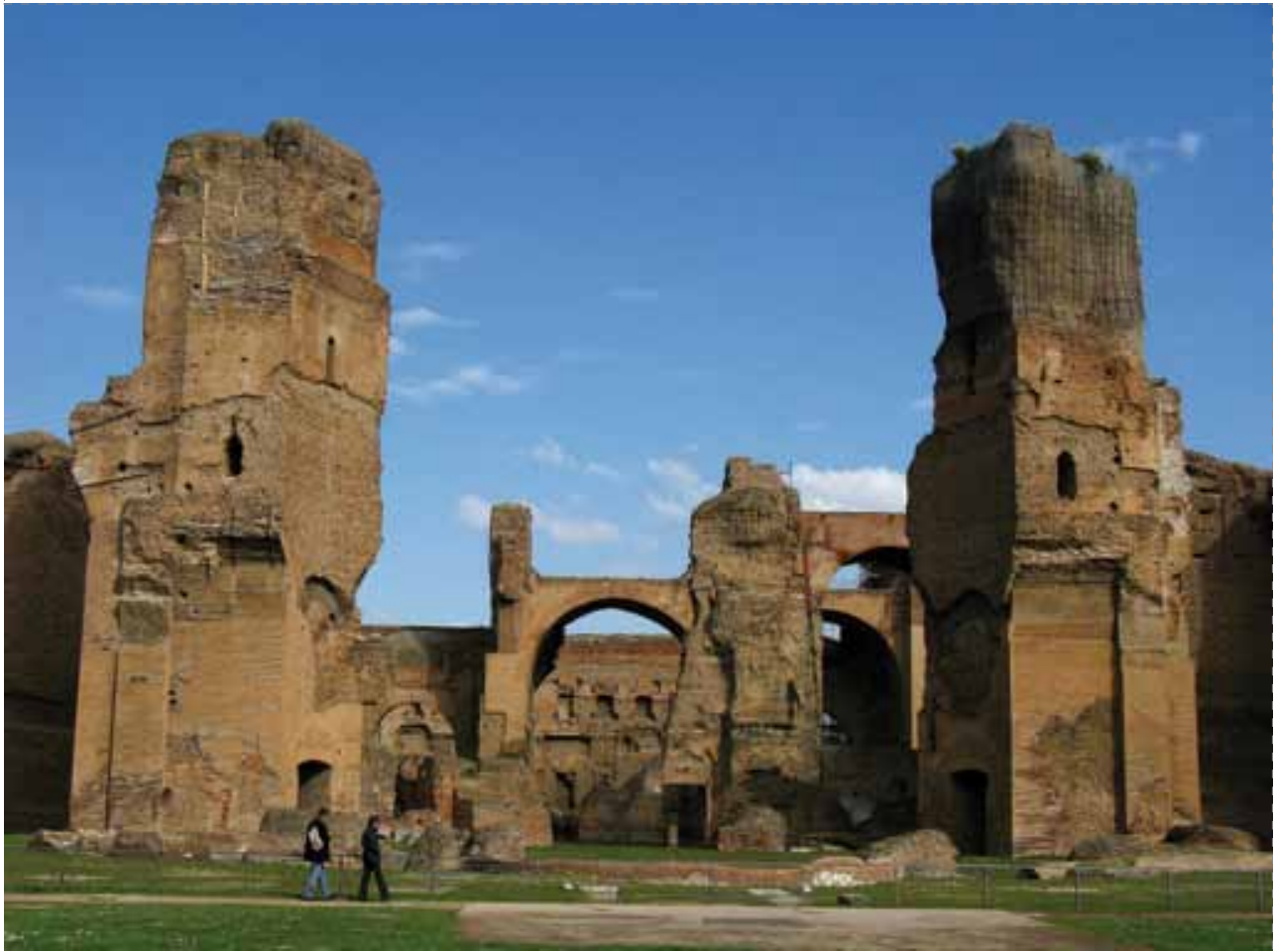

Termas de Caracalla, Roma, febrero de 2008. Fotografía del autor. porciones urbanas casi no es posible alcanzar, desde el punto de vista de la experiencia, un contacto con el pasado del lugar. Es el caso del Parque Bustamante, donde la anterior infraestructura ferroviaria determina su forma, pero de esta ya casi no queda rastro. Sólo un conocimiento histórico o documental permite establecer las asociaciones a través de las cuales se comprende el parque en su condición de huella de una porción ausente de ciudad.

Dado esto, se centrará la discusión en aquellas zonas en que los restos de la antigua infraestructura de ferrocarril aún persisten, al margen de una ciudad que parece transcurrir en un tiempo paralelo, al que no han sido incorporados. Como un ejemplo inverso a esta situación, se pueden mencionar edificios o lugares construidos en el pasado, pero que hoy forman parte del presente de la ciudad. Tal es el caso de la Plaza de Armas de Santiago, donde uso, memoria e identidad confluyen en un espacio de completa vigencia. Esta condición se puede aparejar, por ejemplo, con la Estación Central y la Estación Mapocho, piezas del antiguo sistema ferroviario que permanecen como parte integrante de la actividad urbana contingente, como un pasado inscrito en el presente de la ciudad, es decir, en la literal construcción de su historia.

Por el contrario, no muy lejos de estas estaciones, pero en sus antípodas, emerge un paisaje residual, correspondiente a un pasado no incorporado en la coherencia del espacio histórico de la ciudad. Espacios que tuvieron un neto carácter productivo, que constituían una verdadera trastienda urbana, que se extendía hacia atrás de las estaciones; y que no contaron, como éstas, con una especial significación. Emergen por tanto en su calidad de desecho, donde el vehículo fundamental de memoria, de apropiación del lugar, son estos desnudos vestigios, frágiles y dispersos. Aparecen como la imagen inacabada, imprecisa, pero libre y evocadora de una porción de ciudad ausente, que comparece a través de sus ruinas; por lo que la historia de estos emplazamientos se hace posible como una reconstrucción a través de la vivencia de los mismos.

La manera de comprender la idea de ruina, como se propone aquí, no la considera como un elemento de conservación patrimonial, que podría ser tal vez el marco más tradicional donde situarlas. Dicha concepción la acerca más a una condición monumental y museística, alejándola de sus posibilidades en tanto apertura y crítica con respecto a la ciudad. Conservar una ruina para tener a 
Iglesia conmemorativa Kaiser Wilhelm III, Berlín, enero de 2007 Fotografía de Natalia Spörke.

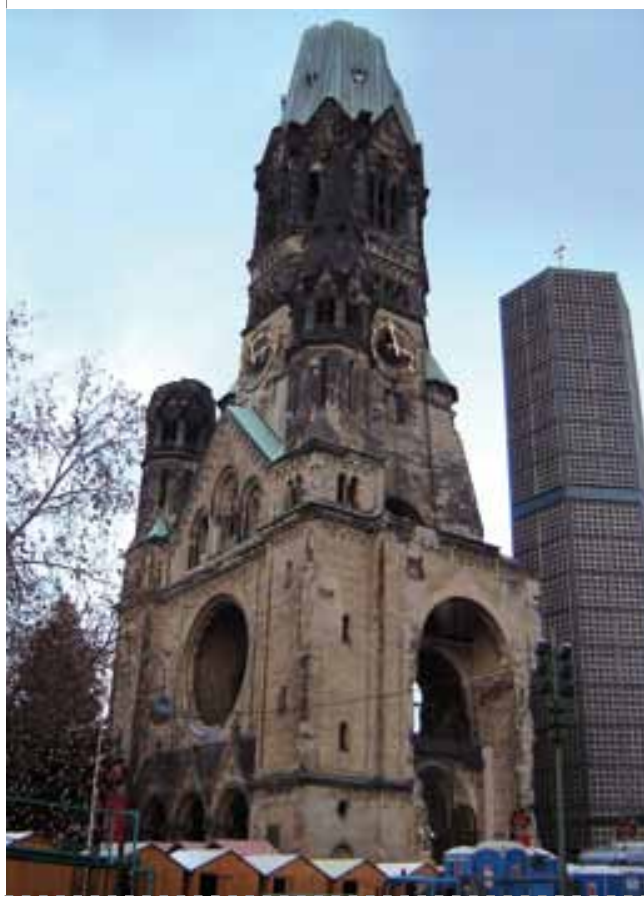

través de ella una aproximación al pasado, ofreciéndola de este modo, constituye una incorporación mediante la cual se le abre un espacio significante en la construcción del orden presente. La presencia de la ruina normalmente va acompañada de placas con reseñas históricas, recintos con objetos o imágenes alusivas a la época «viva» del lugar o edificio. Así, comparece todo reunido, reordenado, controlado y expuesto para que el usuario tenga un cómodo acceso a este pasado reconstruido desde el presente. He aquí la ruina elevada a la categoría de monumento, como institucionalizado objeto de memoria y depositario de la identidad y la cultura de una sociedad.

Ejemplo de lo anterior son las ruinas de las Termas de Caracalla, en Roma, que datan del siglo III de la era de Cristo. Un imponente complejo de baños públicos que representa hoy un importante vestigio de la antigua civilización romana. La importancia de su conservación ha llevado a protegerlas de tal modo que prácticamente se ha detenido su proceso natural de descomposición, es decir, desde cierto punto en el tiempo, estas ruinas, manteniendo su condición inacabada y derruida, devienen materialmente incorruptibles, a través de un proceso químico de desinfección y profilaxis.

Por otra parte están las ruinas que rememoran tragedias históricas, que son dejadas a la contemplación. Si existe un cierto

Entorno de la ex Estación Yungay de Ferrocarriles, Santiago, junio de 2006. Fotografía del autor.

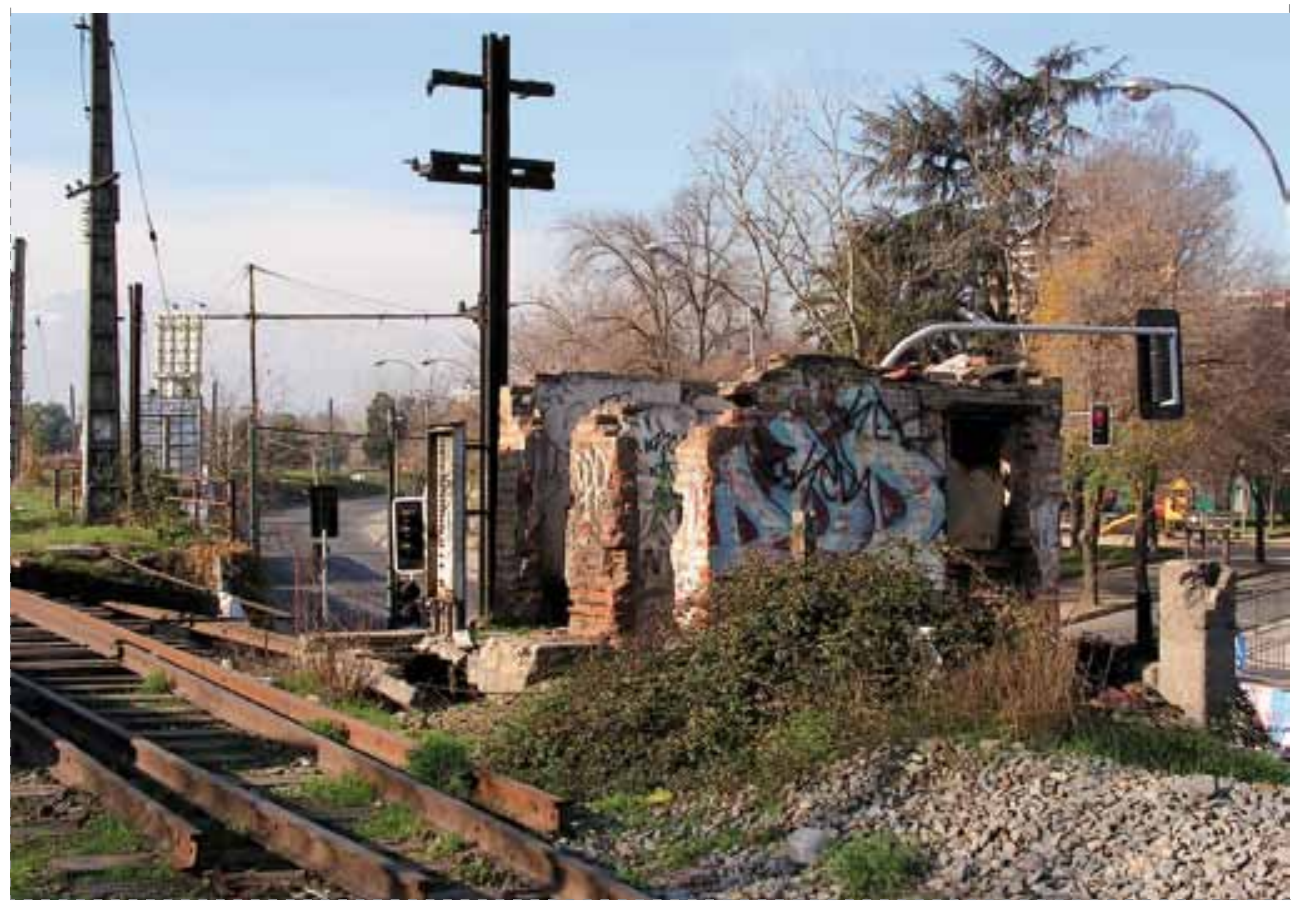

alcance crítico en ellas, está construido intencionalmente desde la misma sociedad como es el caso de la Iglesia Memorial Kaiser Wilhelm, en Berlín, en que las ruinas del antiguo templo construido a finales del siglo xIX, casi desplomado por los bombardeos aliados en 1945, han sido dejadas prácticamente sin restaurar, como testimonio de la guerra.

Pero a los vacíos y vestigios del antiguo ferrocarril de cintura de Santiago, que permanecen inmersos secretamente en la ciudad, no se les ha otorgado este tipo de valoración. Tampoco habría motivo para hacerlo. No son monumentos. Por el contrario, constituyen una realidad impertinente y molesta al regular hábitat de sus entornos: lugares deshabitados, inseguros, insalubres.

Estas ruinas no están «apropiadas», sino «infiltradas» en el espacio de nuestra cotidiana existencia, colándose desde el pasado al presente, sin mediar una incorporación. Irrumpen como signos que han cobrado autonomía al carecer de una función o un sentido actual. Signos críticos, porque además de comportar aquel modo incierto de aparecer, propio de las ruinas, son agentes de crisis de la ciudad funcional, y con ello, elementos de crítica hacia su proyecto. Y no son ruinas de un pasado remoto: sino ruinas modernas, de un pasado reciente y cercano, lo que las hace aún más inquietantes.

Por una parte, constituyen entonces una fisura, un intersticio en los pliegues de la urbe planificada y eficiente del ideal moderno; pero más allá de esto, dan cuenta de aquella condición de desecho, producto residual en la dinámica moderna del desarrollo y el progreso. El sistema ferroviario fue una obra tremenda, sin precedentes en el Santiago de hace ya más de 100 años; que una vez terminada su vida útil; una vez que el progreso da un salto y la deja atrás, se vuelve un despojo. Esta fragilidad remite la frase de Karl Marx, que recoge Marshall Berman, precisamente para explicar la experiencia de la modernidad, en la que todo lo sólido se desvanece en el aire $^{4}$. Luego, si estas ruinas son capaces de despertar una nostalgia, esta debe ser leída en clave moderna.

\section{Alegoría}

La forma en que Walter Benjamin comprende la historia, entrega ciertas nociones a las que se puede asimilar la situación de los territorios del ex anillo ferroviario que aún perviven en medio de la trama urbana. No se 
Ex Maestranza de Vía y Obras (al costado nororiente de la Maestranza San Eugenio de Ferrocarriles), Santiago, junio de 2007. Fotografía del autor.

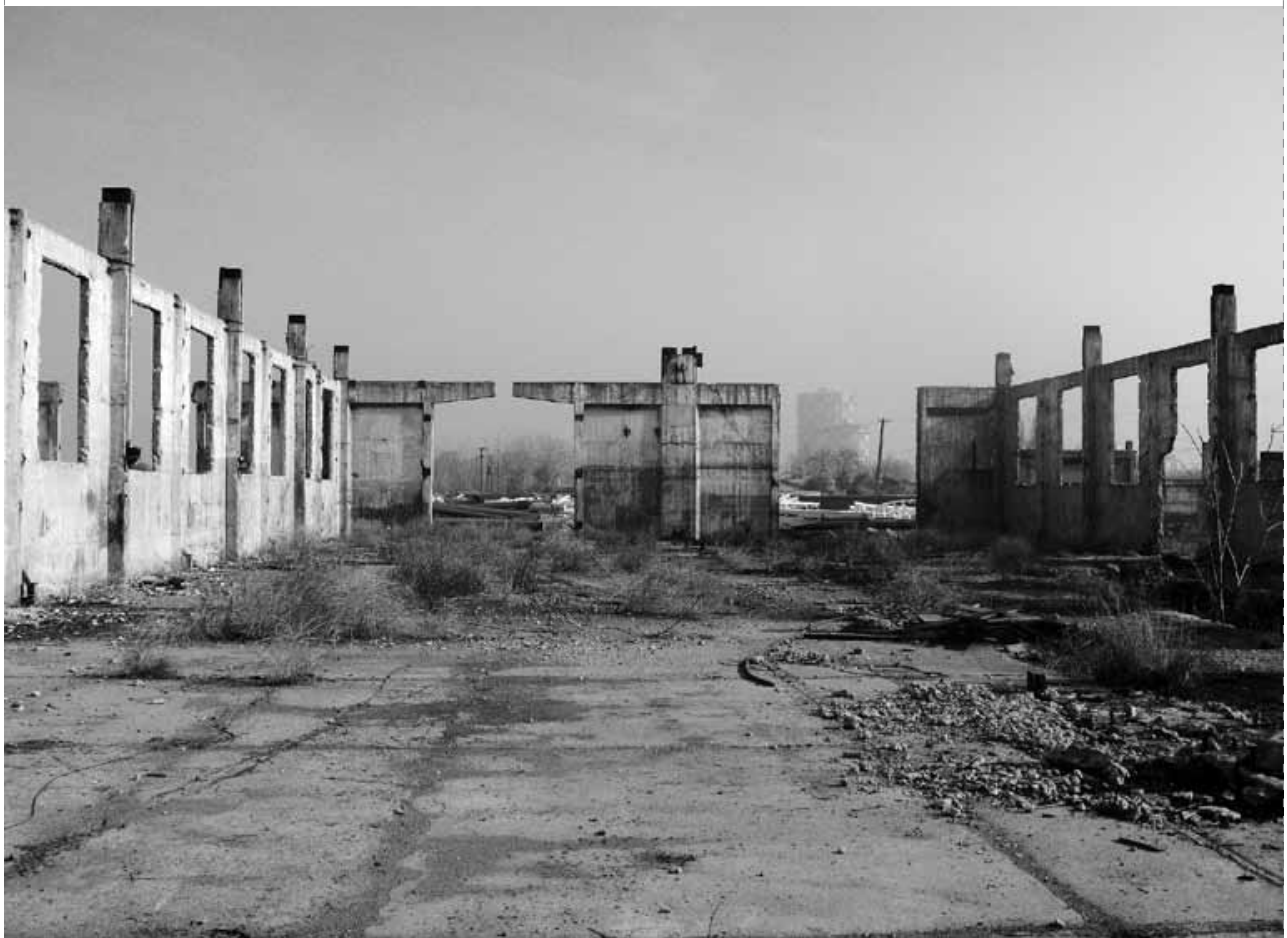

trata de trabar una relación acabada entre el pensamiento de este filósofo y el problema tratado aquí, sino rescatar ciertas nociones sobre las cuales apoyar una explicación respecto al modo en que estas antiguas infraestructuras se presentan a la experiencia y al ejercicio de la memoria, observándolas en su condición a-histórica.

La ciudad contemporánea es en gran medida, el reflejo o materialización actual de la historia en el espacio construido. La historia es lo que se hace presente del pasado, dándole una continuidad y coherencia con que se hace pleno de sentido en la actualidad. Según Benjamin, la historia es contada y articulada por los vencedores, por la fuerza dominante, obliterando aquello que se desvanece en la marcha del progreso. El correlato de esto en la ciudad, se propone que correspondería a los lugares del pasado inscritos en el hábitat presente, que le son funcionales y que conforman parte integrante de su identidad.
Aquello que escapa a esto es destruido o transformado para restituir su coherencia con el todo, en el sentido ideal, moderno, de una ciudad planificada, de un orden urbano eficiente.

La falsa vivacidad de la presentificación, el hacer a un lado todo eco de «lamento» (que brota) de la historia, señala su definitiva sumisión al concepto moderno de la ciencia 5 .

Hay como una ideología de los lugares de la memoria, que se junta con la del patrimonio. Su fondo común es la afirmación de una continuidad entre lo actual y lo pasado $(. . .)^{6}$

Benjamin pone atención en lo que vendría a ser la esencial discontinuidad de la historia, la que se compone fundamentalmente de ciclos fallidos, que no figuran en las representaciones del pasado con un sentido actual, articulando una continuidad que precisamente, se construye desde el tiempo presente. En oposición, el autor presenta una concepción del pasado como «lo sido», reconociendo su condición no vigente, su caducidad que se enfrenta a la concepción moderna y lineal del progreso.

Como un reflejo material de esta idea, encontramos los territorios del ex ferrocarril de cintura de la ciudad: su realidad concreta es la del abandono, cuando no la desaparición de la escena urbana. Estas discontinuidades críticas en el tejido urbano son, a su vez, discontinuidades históricas, en las que se revela la faz decaída de un pasado «sido». Son interrupciones a la ciudad actual, propiciadas por un pasado no reconocido como parte de la misma; pero sin embargo es un pasado que en gran medida dio forma a lo que existe hoy. A pesar de esto, ahora emerge como ajeno a la ciudad vigente, y por consiguiente, extraño a su hábitat regular. Esta condición de recuerdo desconocido sin duda remite a una cierta Unheimlichkeit? ${ }^{7}$, es decir, de aquello que habiendo sido propio o benigno, despierta en el individuo una sensación de extrañeza o desprotección al presentársele como algo ajeno o desconocido.

La mirada sobre un pasado no vigente, a fijarse en el mundo material, se deposita entonces, necesariamente en las ruinas, en los restos de aquello sobre lo cual el dominio presente no ha ejercido la borradura. La interpretación filosófica de tales restos tiene su clave en la alegoría. He aquí que la concepción de historia de Benjamin tiene un correlato en el mundo físico, ya que la alegoría es, en el dominio del pensamiento, lo que las ruinas en el dominio de las $\operatorname{cosas}^{8}$.

En primer término, la alegoría designa un determinado modo de interpretar las Sagradas Escrituras, para descubrir, más allá de lo literal del relato, verdades de carácter permanente, haciendo lógica referencia a los postulados religiosos como modelo interpretativo. Actualmente, si se sigue al Diccionario de la Real Academia Española, corresponde a una figura que representa o significa algo diferente de lo que es, teniendo un sentido literal (evidente) y otro figurado (interpretado). Pero Benjamin propone a

Walter Benjamin. La dialéctica en suspenso: Fragmentos sobre la historia. Traducción, introducción y notas de Pablo Oyarzún sobre textos de: Walter Benjamin. Santiago: Arcis Lom, 1995; p. 74 (Ms 1098). El traductor introduce las palabras puestas entre paréntesis para una mejor comprensión del texto.

Walter Benjamin. Op. cit.; p. 186

Voz alemana que explica la condición de Unheimlich, literalmente traducible como lo in-familiar. Sigmund Freud, desde el punto de vista del psicoanálisis, lo toma para explicar la cualidad de aquello que, habiendo pertenecido a un entorno familiar y benigno, se transforma por distintos mecanismos, en algo desconocido, extraño y amenazante, como podrían ser los espacios abandonados del antiguo ferrocarril, no acondicionados para acoger el hábitat. Las traducciones al castellano usuales para este término son «lo ominoso» o «lo siniestro», que de alguna manera son reductivas en relación a la tensión interna entre lo familiar y lo extraño, razón por la cual se ha recurrido al idioma original. Sigmund Freud. Lo ominoso. En: Obras completas. Vol. XVII. Madrid: Ediciones Biblioteca Nueva España, 1973 (1912); pp. 217-251.

Walter Benjamin. Trauerspiel, I. En: Susan Buck-Morss. Dialéctica de la mirada: Walter Benjamin y el proyecto de los pasajes. Cambridge, Massachusetts: MIT Press, 1989; p. 187. Traducción de Nora Rabotnikof. 
través de esta noción, partiendo de elementos concretos pero fragmentarios, construir toda una interpretación en torno a la historia, alcanzando de esta forma la verdad, por fuera del discurso dominante.

La historia, en todo lo que ella tiene, desde un comienzo, de extemporáneo, penoso, fallido, se acuña en un rostro, no, en una calavera. Y si bien es verdad que a ésta le falta toda la libertad «simbólica» de la expresión, toda armonía clásica de la figura, todo lo humano, no sólo la naturaleza de la existencia humana, sin más, sino la historicidad biográfica de un individuo se expresa como acertijo en ésta, su figura natural más decaída. Este es el núcleo de la consideración alegórica, $(\ldots)^{9}$.

Entonces, en la alegoría se expresa la faz de la historia en tanto pregunta enigmática. Este carácter incierto de la historia se produce a través de su proceso de recaída en la naturaleza, lo que tiene su expresión material en ruinas y fragmentos, los que permanecen como un texto a descifrar o completar. Sin embargo, esta disponibilidad no llega a un resultado único, sino que por el contrario, es necesariamente divergente, descansando en la subjetividad del individuo. Es fundamentalmente este estado expectante del signo, lo que se quiere rescatar como valor en las ruinas y el vacío del ex anillo ferroviario de Santiago. Para efectos del presente texto, se rescata la alegoría como una forma de conocimiento posible, como una lectura respecto a los fragmentos del ex anillo ferroviario de Santiago, el que puede darse a través de la experiencia misma de su residuo material.

Como se ha visto, a la alegoría le precede un vaciamiento del signo, para luego depositar en él una lectura alternativa. Aquí, en los espacios vacíos del ex anillo ferroviario de Santiago, el vaciamiento se hace extensivo a la condición de uso, además del significado. La ausencia, abre perspectivas posibles para la interpretación y el uso, lo que lleva aparejado un ejercicio de la memoria como imaginación. Una memoria de lo incierto: sobre lo que pudo haber o sobre lo que puede haber ahí.
Ex Maestranza de Vía y Obras, Santiago junio de 2008 . Fotografía del autor.

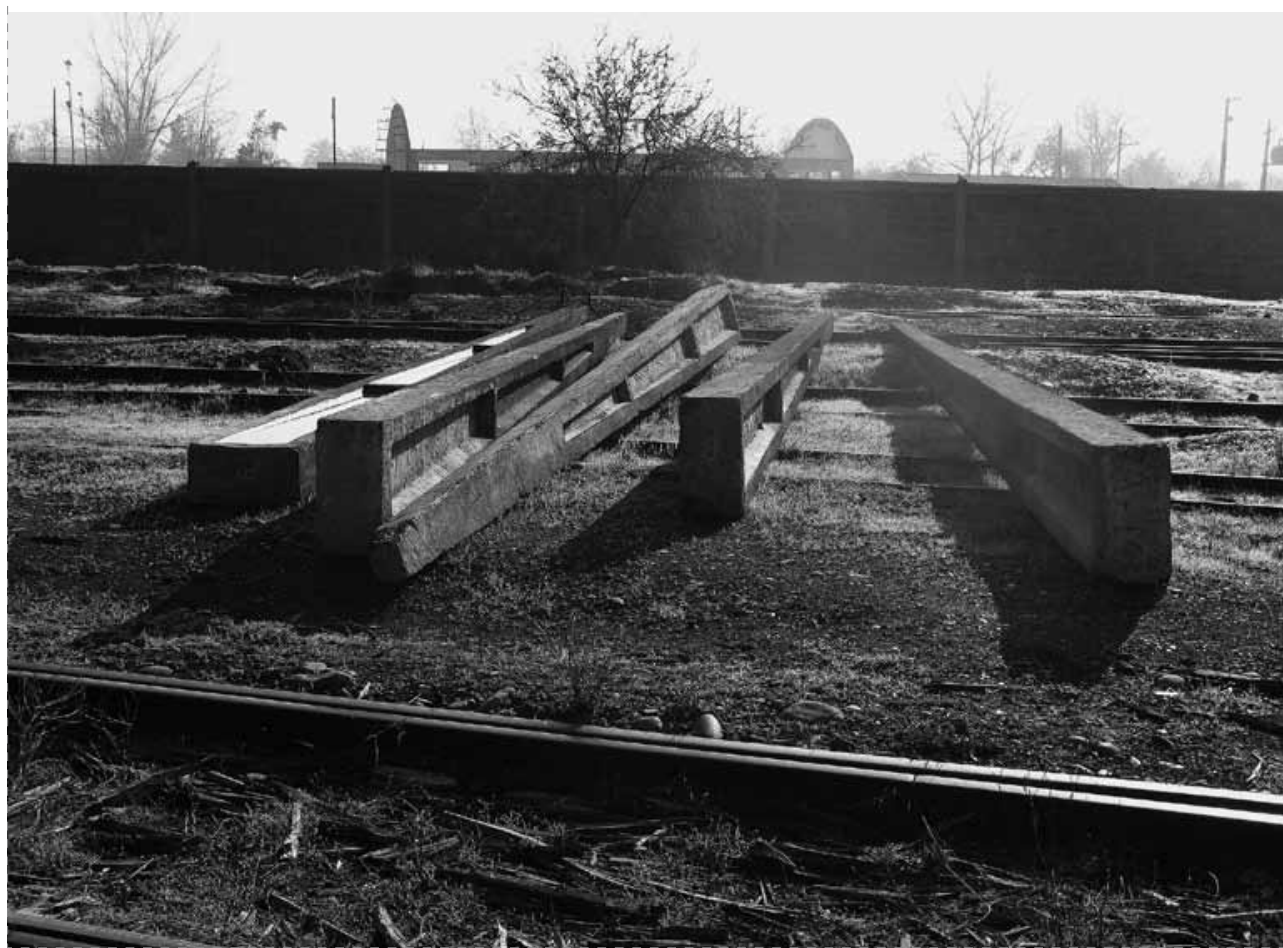

La pregunta se dirige en ambos sentidos de la línea del tiempo, saliéndose de la superficie de la actualidad y explorando lo que ésta no es capaz de contener. De esta forma, las ruinas de algo que se deteriora pueden ser tomadas, inversamente, como los cimientos de una ciudad inconclusa ${ }^{10}$

Reconocer los territorios del antiguo anillo ferroviario como génesis del desarrollo urbano, pero en su condición presente de decaimiento, de ruina; equivale, como se ha planteado aquí, a reconocer un pasado no vigente de la ciudad. Pero efectivamente, este ejercicio de la memoria, que lleva a una dimensión casi literal el pensamiento de Benjamin, no se limita a una observación y reflexión sobre un pasado trunco, sino que éste además se orienta a un futuro aún posible, por lo que se propone, que el lugar material de una utopía no cumplida (en este caso de la modernidad temprana, de aquel progreso que venía de la mano del ferrocarril), permanece aún abierto, disponible. Su condición actual es la que revelaría Robert Smithson: la de un futuro abandonado ${ }^{11}$.

El futuro, concebido como diferencia del presente, como hiato que se abre en éste, irresuelto, proviene, no de unas virtualidades que estarían alojadas e implicadas en dicho presente, sino del pasado en cuanto cual puede brotar el futuro es la fisura que el pasado pendiente inscribe en el presente. Que el pasado permanece pendiente, esto es lo decisivo en la concepción benjaminiana ${ }^{12}$.

Ahora bien, el acercamiento a este tipo de territorios, ya desde el campo disciplinar de la arquitectura, introduce una lectura que es coherente y complementaria con la presentada hasta aquí. La noción de terrain vague, acuñada por Ignasí de Solá-Morales a mediados de los noventa para definir lo que pendiente. La diferencia del presente, de la

Walter Benjamin. La dialéctica en suspenso: Fragmentos sobre la historia. Santiago: Arcis Lom, 1996; p. 16. Traducción y notas de Pablo Oyarzún. Texto original: Walter Benjamin. Gesammente Schriften, I-1; p. 343.

10 La dimensión trágica del drama histórico (guerras, genocidios, revoluciones), que abarca la filosofía de Benjamin, y que tienen un alcance sociocultural más traumático; no está presente en las ruinas del ex anillo ferroviario de Santiago, tampoco las reivindicaciones de una clase social oprimida. Sencillamente se trata aquí de articular una mirada sobre la presencia de la ausencia de este sistema férreo en la ciudad, su dimensión histórica (o a-histórica) y su modo de aparecer a la experiencia. Para esto, Walter Benjamin ofrece un marco conceptual rico y significativo, hacia el cual se ha aventurado este acercamiento.

1 Robert Smithson, en el año 1967, realiza una excursión en las riberas del río Passaic, en Nueva Jersey. Construye un registro interpretativo a partir de textos y fotografías que dan cuenta del recorrido a través de un territorio desarticulado y periférico, una autopista en construcción y su entorno contaminado y decadente. A partir de éste extrae diversas lecturas que significan una nueva aproximación a los denominados por él como paisajes entrópicos, que surgen en los márgenes de la modernidad. Robert Smithson. Un recorrido por los monumentos de Passaic, New Jersey. Barcelona: Gustavo Gili, 2006.

12 Pablo Oyarzún. Nota en: Walter Benjamin. Op. cit.; p. 29. 
el designa como la forma de la ausencia ${ }^{13}$ en la ciudad, surge como interpretación sobre el fenómeno de los vacíos urbanos dejados por las antiguas infraestructuras industriales y ferroviarias, recogiéndolos a la vez como evocación y provocación. La idea de terrain vague no sólo contempla una forma incierta en que aparece un pasado hipotético, no formalizado por la urbe; sino que conjuga también el elemento de la promesa, de la expectativa sobre lo posible que ha de ocurrir allí. Referidos como lugares internos a la ciudad, pero externos a su uso cotidiano, exteriores mentales en el interior físico de la ciudad, que aparecen como contraimagen de la misma, tanto en el sentido de su crítica como en el de su posible alternativa ${ }^{14}$.

La relación de un pasado pendiente, que está en potencia, en expectativa, como plantea Walter Benjamin; con la condición de promesa que sugiere Solá-Morales al definir el terrain vague, se hace evidente. A través del concepto de alegoría se puede explicar la condición abierta y evocadora de un terrain vague. Pero la interpretación como memoria y acción de un habitante en el lugar, registrar esta experiencia es, aquí, imposible, puesto que recae en la subjetividad de cada individuo. Sin embargo, es posible plantear ciertas claves para comprender la memoria a partir de la experiencia de estas infraestructuras en la ciudad actual, desde su condición de ruina, de ausencia.

\section{Anamnes is}

Mientras la amnesia designa una pérdida o debilidad notable de la memoria, la anamnesis sugiere la recuperación a través de una representación o traída a la memoria de algo pasado. Este significado es compartido por la palabra reminiscencia, que a su vez quiere decir recuerdo vago e impreciso ${ }^{15}$. Tales cualidades respecto a lo que se recuerda, son asimilables a los vestigios del ex anillo ferroviario de Santiago: lo que se dispone para una reconstrucción posible a partir de una memoria desde sus fragmentos. Esto es una apertura al juego libre de una memoria como imaginación; y a su vez, a una acción que reinterpreta un territorio, sobre el que se pueden depositar nuevos usos y significados. Pero por otra parte, constituye igualmente un encuentro con el olvido, con lo que ha sido dejado de lado, lo no inscrito en el presente de la ciudad: "lo sido», según lo recogido de Walter Benjamin. Estos son los márgenes críticos de la memoria, porque están situados entre memoria y olvido: lo que falta se hace evidente, así aparece la ausencia. Pero este contacto es frágil y momentáneo, ya que se produce en un territorio que aparece en ruinas, y como tal, recorre su proceso de desaparición, hacia la completa borradura.

La anamnesis, en esta tensión entre memoria y olvido, opera en la acción mnemónica del habitante sobre aquellas porciones urbanas que conforman un pasado no vigente de la ciudad. Sin embargo, esto implica, desde el punto de vista metodológico, una superposición entre la dimensión general y abstracta de ciudad, y la experiencia particular, interna del individuo. ¿Hasta qué punto es posible reflexionar sobre una conjunción de estos ámbitos? ¿De qué forma articular este acercamiento?

Un ejemplo en este sentido, lo constituye la propuesta de Sébastien Marot, que al recoger un planteamiento de Sigmund Freud y apoyarlo en la teoría de los marcos sociales de la memoria, de Maurice Halbwachs, plantea la idea de que entre la memoria psíquica y la memoria urbana podría existir no sólo una relación de analogía formal, sino incluso alguna forma de consustancialidad ${ }^{16}$.

En su libro El malestar de la cultura, de 1930, Freud analiza el problema de la conservación psíquica de sentimientos y recuerdos, los que según él, quedarían siempre grabados, no desapareciendo nunca de la psique. Para explicar dicha idea, Freud propone una metáfora a través del análisis de Roma, bajo e supuesto de que fuera ésta un ente psíquico de gran riqueza. Un acceso simultáneo a todas sus capas históricas significaría, por ejemplo, la superposición de edificios de épocas distantes en un mismo lugar, que aparecerían sólo con cambiar el punto de vista o dirección de la mirada sobre éste. Freud luego desecharía esta fantasía por absurda, aduciendo la imposibilidad de representar a través de ella la vida psíquica. Pero a pesar de esto, rescata ciertos aspectos de su hipótesis inicial, estableciendo que sería posible acceder al pasado psíquico, que éste no necesariamente desaparecería por completo. No obstante, el interés que ve Marot en esta hipótesis, es su posibilidad de tomarla de manera inversa, es decir que la ciudad puede ser analizada como un ser psíquico, como un ser cuyos estados anteriores son accesibles de modos diversos, y en el que el espesor del espacio-tiempo, de transparencias y opacidades, está más o menos a disposición del viaje de la memoria17

La emergencia del pasado en el presente podría entonces, verse favorecida en algunas regiones de la ciudad más que en otras, y de modo similar en que Freud establece que los estratos psíquicos desaparecidos podrían alcanzarse en condiciones favorables, como, por ejemplo, mediante una regresión de suficiente profundidad ${ }^{18}$, ciertos estratos ocultos del pasado urbano podrían revelarse a la memoria de sus habitantes. Luego, en esta analogía entre ciudad y psique ¿Qué lugar ocuparían los espacios del ex anillo ferroviario de Santiago?

Esta aproximación sugiere asimilar el presente activo de la ciudad y su memoria histórica con aquellas zonas de la psique vinculadas a la conciencia. Una memoria coherentemente integrada en la cotidianidad, versus un pasado olvidado (reprimido en la conciencia y abandonado, no vigente), pero que, sin embargo, brota como una extraña irrupción en el espacio y tiempo de la ciudad contingente, como si ciertas regiones de su subconsciente emergieran en forma crítica, aún no asimiladas en la construcción de un orden urbano con uso y sentido actual.

Ahora bien, este tránsito propuesto entre la dimensión de lo psíquico y la dimensión de lo urbano, se produciría, tal vez de manera muy lógica, en la dimensión de lo colectivo. La teoría de los marcos sociales de la memoria de Maurice Halbwachs proporciona, según Marot, una base rigurosa a la hipótesis tomada de Freud. La teoría actúa sobre la base de que habría que buscar el lugar donde se ubica la memoria más en la sociedad que en el individuo, lo que llevaría a comprenderla como organizada a través de elementos comunes y estables, extendidos dentro de un ámbito cultural o social. Esto se apoya fuertemente en el mundo físico, que en su condición concreta y más o menos estable, sería capaz de fijar

\footnotetext{
Ignasí de Solá-Morales. Territorios. Barcelona: Gustavo Gili, 2000; p. 186.

4 Ignasí de Solá-Morales. Op. cit.; p. 188

Definiciones en el Diccionario de la Real Academia Española.

6 Sébastien Marot. Suburbanismo y el arte de la memoria. Barcelona: Gustavo Gili, 2006. p. 52

Sébastien Marot. Op. cit.; p. 60.

18 Sigmund Freud. El malestar de la cultura (1930). Madrid: Alianza Editorial, 1999; pp. 12-13. En: Sébastien Marot. Op. cit.; p. 44.
} 


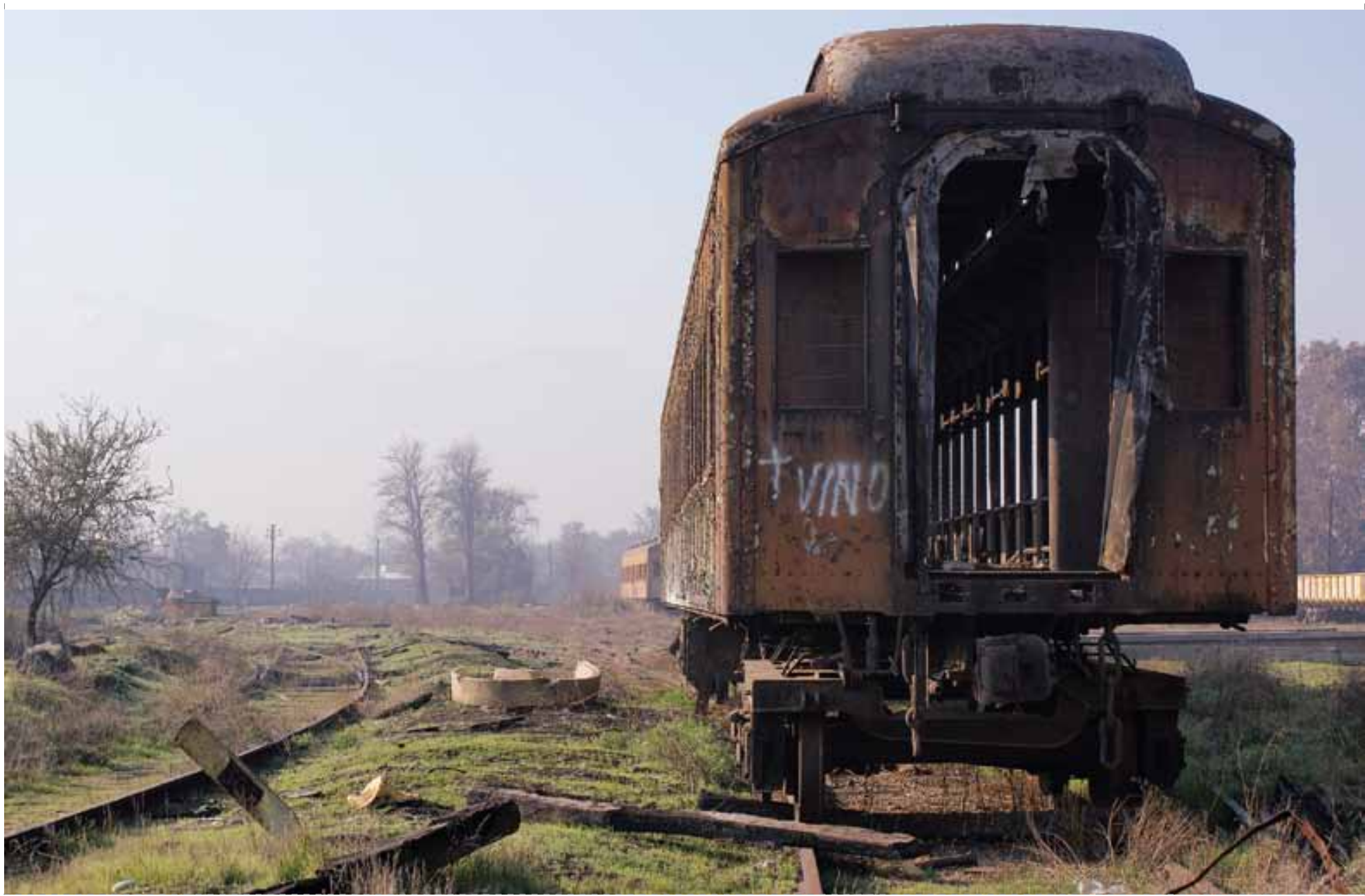

y organizar los recuerdos. En ese sentido, Marot recoge de Halbwachs la idea de que el espacio, para la memoria colectiva, es como una imagen inmóvil del tiempo ${ }^{19}$.

\section{(...), la memoria no puede ser asimilada} a una estancia íntima de la conciencia individual, donde cada individuo conservaría sus reservas de recuerdos propios, sino más bien a un proceso de reconstrucción, es decir, a una vía de localización y figuración que funciona esencialmente a partir de referencias socialmente elaboradas (el lenguaje, las particiones del tiempo y del espacio, etc. $)^{20}$.

Al reconocer estos marcos organizadores que de alguna manera sistematizan en lo colectivo el ejercicio individual de la memoria, aparece como más plausible una comprensión psíquica de la ciudad, en su condición de locus de la memoria colectiva, como la define Aldo Rossi. Dentro de esto, también se hace algo más plausible la identificación de estos espacios de la ausencia como aquellas regiones en que aparece un pasado no asimilado en el presente de la urbe, es decir, como ubicado en su subconsciente ${ }^{21}$.

¿No tenemos a veces la sensación de que ciertos lugares o barrios son amnésicos, mientras que otros, por el contrario, guardan la memoria encerrada en la imagen impregnada de un pasado que se presenta como tal? Ahora bien, si experimentamos este sentimiento, ¿no será que estamos experimentando, por o demás, una forma de elasticidad espacio temporal, en la que nos basta efectivamente con «cambiar la dirección de la mirada o la posición que ocupamos» para que la memoria navegue a placer? También sería posible que ciertos lugares de las ciudades y del territorio hayan sido designados y concebidos expresamente, a partir de un momento dado de nuestra historia, para satisfacer el juego libre de la conciencia y la imaginación retrospectiva. Una vez más, estamos pensando en los jardines: en primer lugar, claro está, por la puesta en escena de la ruina y del fragmento, (...) pero, por sobre todo, por la capacidad, que a veces han sabido conservar, para practicar en medio del teatro urbano y de

19 Sébastien Marot. Op. cit.; pp. 53-54.

20 Sébastien Marot. Op. cit:; p. 54.

21 Según Sigmund Freud, es efectivamente en el subconsciente que emerge la condición de Unheimlichkeit (ver referencia 5), poniendo en jaque la estabilidad y coherencia interna del ser. El fenómeno de los territorios e infraestructuras abandonadas en la ciudad, al menos sugiere una segunda analogía posible de desarrollar entre las dimensiones de lo psíquico y lo urbano. 
su presente, un agujero, un espacio vacante en el que todas las épocas de la ciudad están presentes de un modo virtual y simultáneo, puesto que ninguna de ellas se impone en su opacidad construida 22

En el ex anillo ferroviario de Santiago, el lugar de los jardines es tomado por los terrain vagues, que constituyen el remanente de un pasado no inscrito en la estructura presente de la dinámica urbana. Un provocador agente de incertidumbre que desarma el orden de una ciudad unívoca, pero que constituye también una apertura que evoca la multiplicidad de dimensiones de una ciudad que comparece en la medida de su ausencia.

No obstante lo anterior, y retomando la perspectiva de los marcos sociales de la memoria, habría que distinguir que en lo colectivo, el encuentro con un pasado pertinente a la ciudad, pero hoy extraño a su presente, tiene distintas formas según quienes lo experimentan. Por ejemplo, hay quienes trabajaron en esos lugares o que han vivido en los barrios aledaños, por lo que han tenido un acercamiento a éstos en su funcionamiento anterior. En ellos es un pasado tangible, propio de su experiencia de vida. Hay otros que tienen una relación más remota, con algún conocimiento de lo que fueron estos espacios; y también quienes sin tener idea alguna de anterior funcionamiento del ferrocarril (quizás la mayoría), de pronto se encuentran con ciertos vestigios y lugares que en su ruinosa evidencia física remiten a un pasado del que sólo se observa un remanente fragmentario. Estas consideraciones podrían ayudar a establecer, en adelante, de modo más preciso las formas en que la memoria urbana toma cuerpo en cada uno de sus habitantes, comprendiendo que los restos materiales de aquel pasado no inscrito en la dinámica actua de la ciudad, en su condición de ausencia y extrañeza, tienen distintas maneras de aparecer ante éstos.

\section{Nostalgia}

Más allá de la especificidad subjetiva de cada individuo en su relación con los territorios estudiados, existen ciertas condiciones que trascienden hacia lo colectivo o lo intersubjetivo, y que enmarcan dicha relación. Al menos bajo ese argumento es que se han planteado las lecturas precedentes. Una consecuencia entre éstas y la acción desde el proyecto de arquitectura, iría en el sentido de recoger e interpretar la condición compleja y abierta de estos territorios, comprendiendo su amplia dimensión socia y cultural, o sea, reconocer las claves que establece Ignasí de Solá-Morales en torno a la idea de terrain vague. Sin embargo, en las acciones concretas que suelen verse, apenas comparece la condición de vacío como oportunidad para volver a «llenar» con un proyecto; o del rescate histórico como forma de conservación y valoración ${ }^{23}$, pero no como herramientas efectivas de intervención que reconozcan el problema aquí planteado. Entre estas soluciones y la actual condición de los fragmentos que van quedando del ex anillo ferroviario de Santiago, existe aún un margen de exploración que puede situar estas ruinas en el potencial de su dimensión como espacio público: un paisaje abierto a la evocación de un pasado que en lugar de absorberse completamente en el presente, puede dejarse a cierta distancia, en su condición de ausencia.

Propiciar esta apertura involucra la posibilidad de un proyecto, una intervención que deposite un nuevo sentido en este territorio, pero conservando en alguna medida, la autonomía y apertura del signo: aquella distancia, aquella extrañeza que aún lo separaría de su completa inclusión en la superficie de la actualidad. Y si la pregunta apunta al proyecto en estos territorios, antes lo hace hacia las formas representación de los mismos: ¿cómo construir una imagen de éste, que lo eleve efectivamente a la condición de paisaje, en base a aquellos valores de la promesa, de la incertidumbre, de la evocación de un pasado y un presente, abiertos a ser recreados cada vez?

Este problema cobra relevancia en el marco de nuestra cultura contemporánea, ya que esta condición de promesa que posee el terrain vague, observada por Solá-Morales en los vacíos que determinan la forma de la ausencia en la ciudad, como lo son los territorios de antiguo sistema ferroviario de Santiago, es la que da precisamente un lugar posible, un escenario contingente a la utopía no cumplida de una modernidad anterior, pendiente, aún vigente como posibilidad, en los intersticios de la metrópoli de hoy.

Sentimos nostalgia por las ruinas de la modernidad porque todavía parecen transmitir una promesa que se ha desvanecido en nuestra época: la promesa de un futuro diferente ${ }^{24}$

22 Sébastien Marot. Op. cit; p. 60.

23 Hace ya algunas décadas, ha surgido en este sentido un creciente interés por estudiar y rescatar infraestructuras industriales o productivas correspondientes a la temprana modernidad tecnológica. Los conceptos de arqueología industrial y patrimonio industrial, envuelven una problemática nueva, que se ocupa de emplazamientos como aquellos correspondientes al ex ferrocarril de cintura de Santiago. Sin embargo, este afán casi no se ha orientado a discutir las problemáticas tanto arquitectónicas, como urbanas y culturales referidas en el presente artículo.

Y salvo excepciones, tampoco la disciplina de la arquitectura ha presentado un desarrollo o avance significativo sobre los planteamientos de Solá-Morales, tanto en la continuidad teórica como en la aproximación desde el ámbito proyectual.

24 Andreas Huyssen. La nostalgia por las ruinas. En: Miguel Hernández-Navarro. Heterocronías. Tiempo, arte y arqueologías del presente. Murcia: CENDEAC, $2008 ;$ p. 55. Traducido al castellano por María Velásquez, del texto original en inglés: Nostalgia for ruins, aparecido en la revista Grey Room 2006; 23. 